\title{
IgM ganglioside GM1 antibodies in patients with autoimmune disease or neuropathy, and controls
}

\author{
A S Bansal, B Abdul-Karim, R A Malik, P Goulding, R S H Pumphrey, A J M Boulton, \\ P L J Holt, P B Wilson
}

\begin{abstract}
Aims-To compare the titre of antiganglioside antibodies (AGA) to GM1 ganglioside in patients with central and peripheral neurological disease and pure motor and sensorimotor neuropathy, in patients with classic autoimmune diseases, and controls.

Methods-AGA to GM1 were measured using an enzyme linked immunosorbent assay (ELISA) technique, highly purified bovine GM1 ganglioside, and sequential dilution of control and test sera. Antibody titre was calculated using the optical density readings of three consecutive serum dilutions multiplied by the dilution factor.

Results-A considerable overlap was evident in the titre of AGA to GM1 in control and test sera. High antibody titres were most frequent in patients with multifocal motor neuropathy with conduction block (MMNCB). Low AGA titre were observed in several patient groups. Compared with the controls, the median titre of AGA to GM1 was significantly higher in patients with multiple sclerosis, rheumatoid arthritis, primary Sjögren's syndrome and systemic lupus erythematosus. In contrast, the median titre in patients with diabetic peripheral neuropathy, motor neurone disease, sensorimotor neuropathy and chronic inflammatory demyelinating polyneuropathy was no different from that in normal control subjects.

Conclusions-Estimation of AGA to GM1 may be helpful in the diagnosis of
\end{abstract}

Diagnostic criteria for each patient group

\begin{tabular}{|c|c|c|}
\hline Patient group & Number & Clinical criteria \\
\hline $\begin{array}{l}\text { Systemic lupus } \\
\text { erythematosus }\end{array}$ & 26 & At least four of the 1982 criteria for $S L E^{13}$ \\
\hline Rheumatoid arthritis & 20 & Modified ARA criteria for RA ${ }^{14}$ \\
\hline $\begin{array}{l}\text { Primary Sjögren's } \\
\text { syndrome }\end{array}$ & 14 & $\begin{array}{l}\text { All cases fulfilled Fox's criteria for Primary Sjögren's } \\
\text { syndrome }\end{array}$ \\
\hline $\begin{array}{l}\text { Diabetic peripheral } \\
\text { neuropathy }\end{array}$ & 26 & $\begin{array}{l}\text { Abnormal glucose control with clinical and } \\
\text { neurophysiological evidence of neuropathy }{ }^{16}\end{array}$ \\
\hline Multiple sclerosis & 20 & $\begin{array}{l}\text { Abnormal visual evoked responses and oligoclonal } \\
\text { bands on CSF examination }\end{array}$ \\
\hline $\begin{array}{l}\text { Motor neurone } \\
\text { disease }\end{array}$ & 10 & $\begin{array}{l}\text { Impaired motor function on clinical testing and abnormal } \\
\text { electromyogram analysis }\end{array}$ \\
\hline $\begin{array}{l}\text { Sensorimotor } \\
\text { neuropathy }\end{array}$ & 10 & $\begin{array}{l}\text { Sensorimotor dysfunction on clinical examination and } \\
\text { abnormal EMG and nerve conduction studies }\end{array}$ \\
\hline $\begin{array}{l}\text { Multifocal motor } \\
\text { neuropathy with } \\
\text { conduction block }\end{array}$ & 6 & $\begin{array}{l}\text { Clinical features and characteristic findings on nerve } \\
\text { conduction studies }\end{array}$ \\
\hline $\begin{array}{l}\text { Chronic inflammatory } \\
\text { demyelinating } \\
\text { neuropathy }\end{array}$ & 6 & $\begin{array}{l}\text { Clinical features and characteristic findings on nerve } \\
\text { conduction studies }\end{array}$ \\
\hline Healthy controls & 61 & Healthy laboratory workers \\
\hline
\end{tabular}

SLE: systemic lupus erythematosus; ACA: American Rheumatism Association; RA: rheumatoid arthritis; CSF: cerebrospinal fluid; EMG: electromyogram.
MMNCB in patients with a pure motor neuropathy but in few other conditions. Low titre AGA to GM1 are evident in several autoimmune conditions. The pathogenetic importance of AGA to GM1 in patients with neuropathy is not clear.

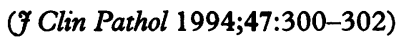

Autoantibodies directed against gangliosides are often polyclonal and of the $\operatorname{IgM}$ isotype. ${ }^{1-4}$ They are characterised by low avidity binding to the carbohydrate moiety of the ganglioside molecule. Although the pathogenic importance of these antibodies is unclear, they are in many cases reactive against the GM1 ganglioside. The latter is the most abundant ganglioside in neuronal membranes but is rare outside the nervous system. ${ }^{5}$ GM1 is exposed at the surface of spinal motor neurones, in contrast to the peripheral nerves where its expression is limited to the node and paranodal region. ${ }^{6}$

Increased titres of antiganglioside antibodies (AGA) have been recorded in many upper and lower motor neurone syndromes. ${ }^{78}$ and several autoimmune conditions, ${ }^{910}$ but very high titres tend to be found in patients with multifocal motor neuropathy with conduction block (MMNCB). ${ }^{571011}$ There is, however, a considerable overlap in the serum titres of AGA found in normal healthy people and patients with autoimmune and neurological disease, ${ }^{47}$ which has led to the recent suggestion that an assessment of antigen to ganglioside antibodies lacks diagnostic specificity. ${ }^{12}$

\section{Methods}

Patients selected for AGA analysis fulfilled the clinical and laboratory criteria detailed in the table. Healthy hospital employees comprised the control group.

Sera were assayed for $\operatorname{IgM}$ antibodies to GM1 ganglioside using an enzyme linked immunosorbent assay (ELISA). Briefly, 96-well microtitre plates (Dynatech Ltd) were coated with $1 \mu \mathrm{g} /$ well of GM1 ganglioside dissolved in methanol. After drying, the plates were blocked with $1 \%$ bovine serum albumin in phosphate buffered saline (PBS). Sera were diluted 40-fold in PBS containing $1 \% \mathrm{BSA}$ and then sequentially double diluted four times in $1 \%$ BSA in PBS. Aliquots (100 $\mu \mathrm{l})$ from each dilution series were transferred into duplicate wells on the coated plate and were incubated for 12 hours at $4^{\circ} \mathrm{C}$. The plates were then washed six times in PBS, patted dry, and then incubated for four hours 
with $100 \mu \mathrm{l}$ per well of horseradish peroxidase conjugated rabbit anti-human IgM diluted 1 in 1000 in $1 \%$ BSA in PBS. After the final wash in PBS the plates were incubated with ABTS and read at $414 \mathrm{~nm}$ in a multiscan spectrophotometer reader. Ganglioside antibody titres were calculated using the optical density of the second to fourth serum dilutions (Sdil) multiplied according to their dilution factor, as indicated in the equation below. The background optical density (OD) was subtracted from the value of the $O D$ at each serum dilution before insertion into the equation below. Plates were developed until the high and low control sera incorporated on each plate gave a value of 1000 and 300 , respectively, when calculated according to this formula.

$\frac{[(\mathrm{OD} \text { at } \mathrm{Sdil} 1 \mathrm{1:80} \times 80)+(\mathrm{OD} \text { at Sdil 1:160 } \times 160)+(\mathrm{OD} \text { at Sdil 1:320 } \times 320)]}{3} \times 1000$

Statistical analysis was performed using the Mann-Whitney U test.

\section{Results}

The figure details the results of IgM AGA titres in all patient groups. Relative to normal controls (median = 59), the AGA titre was significantly raised in patients with $M M N C B$, rheumatoid arthritis (RA), primary Sjögren's syndrome (pSS) and multiple sclerosis (MS) (medians 500, 99, 119 and 96; p < 0.001, $\mathrm{p}<$ $0.007, \mathrm{p}<0.01$ and $\mathrm{p}<0.03$, respectively). Patients with diabetic peripheral neuropathy (DPN) had almost identical results to those of controls. Although not statistically significant, patients with both motor neurone disease (MND) and sensorimotor neuropathy (SMN) had lower titres of AGA than the controls. As we expected the AGA titre in patients with systemic lupus erythematosus (SLE) to be higher than that in the controls a one tailed test of statistical comparison was undertaken. This confirmed that the rise was significant at the $\mathrm{p}<0.05$ level. In patients with chronic inflammatory demyelinating polyneuropathy (CIDP) no significant difference was evident in the titre of IgM AGA to GM1 relative to the

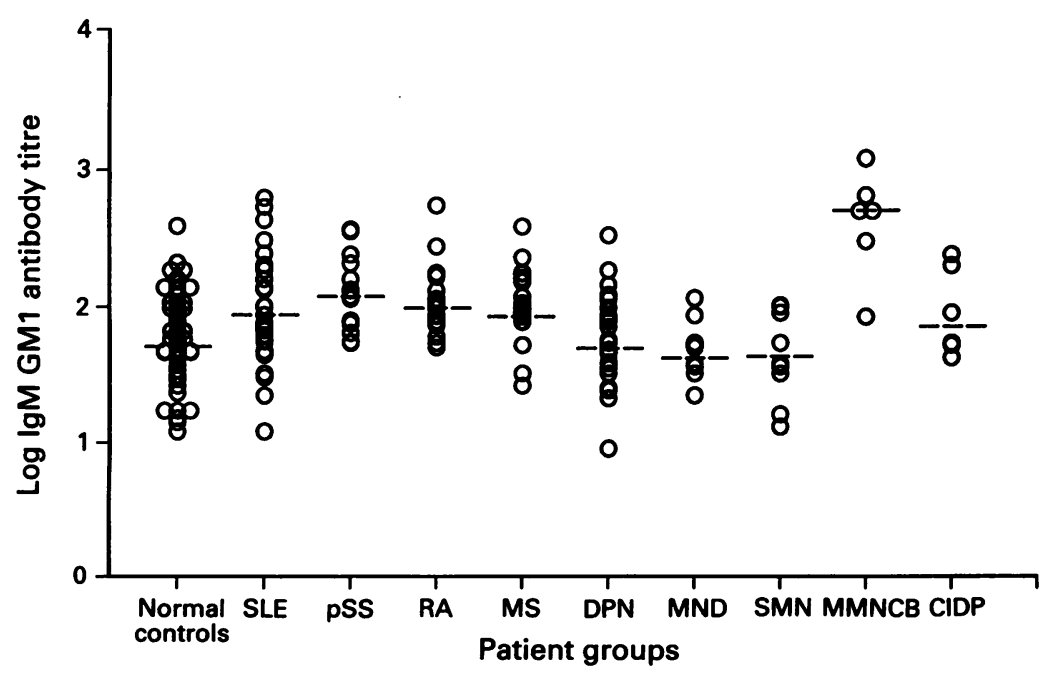

Figure 1 Variation of serum titres of IgM GM1 antibody titres $\left(\log _{10}\right)$ in different patient groups. See text for abbreviations, exact values for the titres, and the results of statistical analysis. control group. The lowest titre of these antibodies was found in patients with non- $\operatorname{IgM}$ myelomas (median 6 , data not shown).

The AGA titre recorded in the controls showed a log normal distribution with a mean titre of 50. Patients with AGA titres above 2 standard deviations of this mean (AGA titre of $>276$ ) were observed in several patient groups. These were most common in patients with MMNCB (5 from 6) but were also evident in patients with SLE, RA, pSS, DPN and MS (3 from 26, 2 from 20, 2 from 14, 1 from 26 and 1 from 20, respectively). Raised titres were not observed in patients with MND, CIDP, and SMN.

\section{Discussion}

The production of IgM autoantibodies by CD5 $\mathrm{B}$ cells is thought to underlie the immune aberration responsible for several autoimmune diseases. ${ }^{17}$ It is, however, unclear whether these autoantibodies are truly pathogenetic or whether they are produced in response to damaged tissue. ${ }^{17}$ In the case of AGA the maintenance of the IgM isotype in the face of continuing clinical disease suggests a dysfunctional regulation of CD5 B cells rather than an antigen driven process in response to nerve damage. The variation of clinical disease with AGA titres ${ }^{18}$ and the demonstration of AGA in the nodes of Ranvier in a patient with MMNCB ${ }^{19}$ does, however, suggest some pathogenic importance. In contrast, raised titres of AGA in controls seems to be incompatible with this notion.

Over the last few years several reports have highlighted the value of AGA measurements in patients with a variety of central and peripheral neurological diseases. ${ }^{1-11}$ These have included $M M N C B$ in particular but also MND, CIDP, and SMN. In most of these situations IgM antibodies to a specific ganglioside (GM1 in most cases) have been increased and IgG AGA have been rarely detected. Problems with assay standardisation have been mooted as an unpredictable factor in the explanation of the differing results obtained by different groups. Our method of AGA estimation uses highly purified GM1 ganglioside, and a coating procedure which has been thoroughly tested in our laboratory and indeed has been used by other groups researching AGA. Subsequent steps in our assay are similar to those used elsewhere and Tween is rigorously excluded from all stages of the assay procedure. ${ }^{3}$ The method of AGA titre analysis has been chosen to allow the maximum information to be obtained from a sequential serum dilution analysis. This produces highly reproducible intra- and interassay results (coefficients of variation $5.4 \%$ and $10.6 \%$, respectively, at calculated antibody titres of 300).

In many ways our results are similar to those of Pestronk et $a l^{24}$; we too found mildly increased titres of IgM AGA to GM1 in patients with SLE and indeed in some normal people. Weller et al, ${ }^{12}$ investigating IgG and IgM antibodies to several gangliosides in a variety of neurological and autoimmune 
diseases, found pathologically raised titres of either IgG or IgM antibodies to at least one ganglioside in almost one third of all patients. Exact antibody titres were not recorded, but they found raised titres of IgM anti-GM1 antibodies in two out of 15 patients with SLE. Adams et $a l,{ }^{7}$ however, reported low titre AGA to GM1 in $60 \%$ of patients with autoimmune disease and Endo $e t \mathrm{al}^{3}$ found such antibodies with relatively high frequency in patients with SLE and MS. In contrast, Sadiq et $a l^{5}$ found AGA titres to be almost identical in controls and patients with SLE and MS. With regard to patients with MS, our negative results are similar to those of the latter group and to the findings of Weller et al. ${ }^{12}$ Our results also extend the list of autoimmune conditions with such increases in IgM AGA to include patients with $R A$ and pSS. In patients with diabetic peripheral neuropathy, CIDP, and SMN our results demonstrate no significant rise in AGA. Weller et al, ${ }^{12}$ while finding no increase in IgM anti-GM1 antibodies in patients with peripheral polyneuropathy, did find increased titres in three out of 14 patients with CIDP. The degree of this rise was however, not mentioned.

In patients with MND we found that the median titre of AGA to GM1 was lower than that in the controls. Using a different method of data calculation, Shy et $a l^{3}$ found the prevalence of IgM antibodies to GM1 in patients with MND to be twice that found in controls. Latov et $a l^{20}$ recorded few patients with MND as having raised titres of IgM AGA to GM1 (17\%) even though eight out of 30 of their patients had IgM paraproteins. This was also observed by Weller et al. ${ }^{12}$

High titre IgM AGA to GM1 (titre of $>500$ ) were observed most frequently in patients with MMNCB. This was particularly so in patients with obvious and widespread weakness. In patients with characteristic multifocal conduction block on nerve conduction analysis, but with mild or localised weakness, normal AGA titres were evident. Mild or localised disease may explain the low prevalence of raised AGA observed by Weller et al ${ }^{12}$ in their patients with MMNCB. In one patient with MMNCB serial measurements of IgM AGA to GM1 were performed. These showed a close correlation with clinical symptoms; high titres were recorded when the weakness was most severe and decreasing titres were observed with clinical improvement. This suggests a pathogenetic role for IgM AGA to GM1 in this specific condition. The demonstration of conduction block induced by the serum of a patient with GM1 AGA provides further support for this argument. ${ }^{19}$

In conclusion, our investigations have confirmed the presence of high titre IgM AGA to GM1 in patients with MMNCB, but in few other conditions. Low titre IgM AGA to GM1 are found in the peripheral blood of patients with MS even though the site of pathologic damage is within the relative immunological isolation of the central nervous system (CNS). The aetiology and clinical importance of these antibodies in MS is even more obscure than in other conditions. The low titre IgM AGA to
GM1 evident in SLE, RA, and pSS may be a feature of the $B$ cell dysfunctional regulation which is often observed in non-organ specific autoimmune disease. ${ }^{18}$ This explanation may also be relevant to the few healthy subjects with similar low titre antibodies. In patients with DPN, CIDP, SMN and MND the absence of AGA to GM1 suggests that nerve damage, irrespective of its location (peripherally or within the CNS), is not sufficient to produce increases in these autoantibodies. High titre IgM AGA to GM1 may, therefore, be aetiologically important in certain types of motor neuropathy while low titre antibodies may only represent B cell dysfunctional regulation. In the diagnosis of peripheral neurological disease we agree with the conclusions of Weller et $a l^{12}$ that serum estimations of IgM AGA are of little diagnostic help, except in those patients with clinical findings suggestive of MMNCB.

1 Bird SJ. Pure motor neuropathy. Curr Opin Neurol Neurosurg 1990;3:704-7.

2 Pestronk A, Adams RN, Clawson L, Cornblath D, Kunel $\mathrm{RW}$, Griffin D, et al. Serum antibodies to GMI ganglioside in amyotrophic lateral sclerosis. Neurology 1988; 38: 1457-61.

3 Shy M, Evans VA, Lublin FD, Knobler RL, HeimanPatterson T, Tahmoush AJ, et al. Antibodies to GM1 and GD1b in patients with motor neuron disease without plasma cell dyscrasia. Ann Neurol 1989;25:511-13.

4 Pestronk A. Motor neuropathies, motor neurone disorders and antiglycolipid antibodies. Muscle Nerve 1991;14: 927-36.

5 Sadiq SA, Thomas FP, Kilidireas K, et al. The spectrum of neurologic disease associated with anti-GM1 antibodies. Neurology 1990;40:1067-72.

6 Corbo M, Quattrini A, Latov N, Heys AP. Localization of GM1 and $G A 1(\beta 1-3)$ GalNAc antigenic determinants in peripheral nerve. Neurology 1993;43:809-14.

7 Adams D, Kuntzer T, Burger D, Chofflon M, Magistris MR, Regli F, et al. Predictive value of anti-GM1 ganglioside antibodies in neuromuscular diseases: a study of 180 sera. $\mathcal{F}$ Neuroimmunol 1991;32:223-30.

8 Endo T, Scott DD, Stewart SS, Kundu SK, Marcus DM Antibodies to glycosphingolipids in patients with multiple Aclerosis and SLE. $\mathcal{f}$ Immunol 1984;132:1793-7.

9 Hirano T, Hashimoto H, Shiokawa Y, Iwamori M, Nagai $\mathrm{Y}$, Kasai $\mathrm{M}$, et al. Antiglycolipid autoantibody detected in the sera from systemic lupus erythematosus patients. $\mathcal{f}$ Clin Invest 1980;66:1437-40.

10 Pestronk A, Chaudhry V, Feldman EL, Griffin JW, Cornblath DR, Denys EH, et al. Lower motor neuron syndromes defined by patterns of weakness, nerve conduction abnormalities, and high titres of antiglycolipid antibodies. Ann Neurol 1990;27:316-26.

11 Baba H, Duane GC, Ilyas AA, Pestronk A, Cornblath DR, Chaudhry $\mathrm{V}$, et al. Anti $\mathrm{G}_{\mathrm{M} 1}$ ganglioside antibodies with differing fine specificities in patients with multifocal motor neuropathy. $¥$ Neuroimmunol $1989 ; 25: 143-50$.

12 Weller M, Stevens A, Sommer N, Dichgans J, Kappler B, Wiethölter H. Ganglioside antibodies: a lack of diagnostic specificity and clinical utility? $\mathscr{f}$ Neurol 1992;239:455-9.

13 Tan EM, Cohen AS, Fries JF, et al. The 1982 revised criteria for the classification of SLE. Arthritis Rheum 1982;25:1271-7.

14 Arnett FC, Edworthy SM, Block DA, McShane DJ, Fries JF, Cooper NS. The American Association 1987 revised criteria for the classification of rheumatoid arthritis. Arthritis Rheum 1988;31:315-20.

15 Fox RI, Robinson C, Kurd J, Michaelson P, Bone R, Howell FV. First international symposium on Sjögren's syndrome: suggested criteria for classification. Scand $f$ Rheumatol 1986;61(Suppl):28-30.

16 Malik RA, Newrick PG, Sharma AK, Jennings A, Ah-See AK, Mayhew TM, et al. Microangiopathy in human diabetic neuropathy: relationship between capillary abnormalities and the severity of neuropathy. Diabetologia 1989;32:92-102.

17 Raveche ES. Possible immunoregulatory role for CD5 + B cells. Clin Immunol Immunopathol 1990;56:135-50

18 Pestronk A, Cornblath DR, Ilyas AA, Baba H, Quarles $\mathrm{RH}$, Griffin JW, et al. A treatable multifocal motor neuropathy 24:73-8.

19 Santoro M, Uncini A, Corbo M, Staugaitis SM, Hays AP, Latov N. Experimental conduction block induced by serum from a patient with anti-GM1 antibodies. $A n n$ Neurol 1992;31:385-90.

20 Latov N, Hays AP, Donofrio PD, et al. Monoclonal IgM with unique specificity to gangliosides $G_{1}$ and $G_{1 b}$ and to lacto-N-tetraose associated with human motor neuron disease. Neurology 1988;38:763-8. 